\title{
O conhecimento dos professores de educação física do município de Turvo/SC acerca das tendências pedagógicas críticas
}

The physical education teachers' knowledge from Turvo city, in SC state, about the critical pedagogical trends

El conocimiento de los profesores de educación física del municipo de Turvo/SC sobre las tendencias pedagógicas críticas

Loisleine Fernandes Ferreira ${ }^{\mathrm{I}}$, Ana Lúcia Cardoso II

\begin{abstract}
Resumo
O estudo investigou qual o conhecimento dos professores de Educação Física do município de Turvo/SC sobre as tendências críticas da Educação Física, sendo essas a Crítico Emancipatória, Crítico Superadora e também Aulas Abertas. Efetivamos uma pesquisa de campo, tendo como instrumento de coleta de dados, um questionário. Tivemos cinco professores de Educação Física participantes desta pesquisa. Concluímos que a maioria dos professores pesquisados conhecem as propostas críticas da Educação Física.
\end{abstract}

Palavras-chave: Educação Física; Tendências pedagógicas críticas; Conhecimento

\begin{abstract}
The study investigated the physical education teachers' knowledge from Turvo city, in SC state, about the critical pedagogical trends, considering Physical Education, being these as critical emancipatory, critic overcoming and also open classes. We made a field research, having as a data collection instrument, a questionnaire. We had five Physical Education teachers participating in this research. We conclude that the majority of respondent teachers know the critical proposals of Physical Education.
\end{abstract}

Keywords: Physical Education; Critical pedagogical trends; Knowledge

\footnotetext{
${ }^{\text {I } U n i v e r s i d a d e ~ d o ~ E x t r e m o ~ S u l ~ C a t a r i n e n s e ~-~ U N E S C ~-~ C r i c i u ́ m a, ~ S C, ~ B r a s i l ~-~ E n d e r e c ̧ o: ~ R u a ~ d o s ~ C e d r o s ~ 52, ~ B a i r r o ~ S a ̃ o ~ S i m a ̃ o, ~ C r i c i u ́ m a-~ S C, ~ B r a s i l ~-~ e-m a i l: ~}$ lois_ff@hotmail.com

II Universidade do Extremos Sul Catarinense - UNESC - Criciúma, SC, Brasil - e-mail: anc@ unesc.net
} 


\section{Resúmen}

El estúdio investigo cuál es el conocimiento de los profesores de Educación Física del municipo de Turvo/SC sobre las tendencias pedagógicas críticas de la Educación Física, siendo éstas la Crítica Emancipatoria, Crítica Superadora y también Clases Abiertas. Efectuamos una búsqueda de campo, teniendo como instrumento de recolección de datos, un cuestionario. Hemos tenido cinco profesores de Educación Física participantes en esta búsqueda. Conculimos que la mayoría de los profesores encuestados conocen las propuestas críticas de la Educación Física.

Palavras clave: Educación física; Tendencias pedagógicas críticas; Conocimiento

\section{Introdução}

A curiosidade em pesquisar este tema surgiu a partir das realizações de estágios obrigatórios do curso de Educação Física - Licenciatura, em escolas, onde encontramos dificuldades em identificar as tendências pedagógicas nas aulas e os professores supervisores demonstravam não ter clareza sobre as mesmas, especialmente se tratando das tendências críticas.

Outro aspecto relevante foi que durante a formação inicial aprofundamos as tendências críticas da educação física e as mesmas fundamentam os estágios obrigatórios, que ocorrem há 13 anos nas escolas do extremo sul catarinense.

Sendo assim, definimos o seguinte problema para ser analisado: qual o conhecimento dos professores de Educação Física das escolas públicas do Município de Turvo - SC sobre as tendências críticas da Educação Física?

O objetivo geral desdobrou-se em: Compreender qual conhecimento dos professores de Educação Física das escolas públicas do Município de Turvo - SC sobre as tendências críticas da Educação Física. E os objetivos específicos foram: Refletir sobre o que são e qual a intencionalidade das tendências críticas para Educação Física; Identificar qual o conhecimento dos professores acerca das tendências pedagógicas na Educação Física; Perceber se a formação inicial e a formação continuada contribuíram para a apropriação do conhecimento acerca das tendências críticas da Educação Física.

No sentido de buscar responder a problemática da pesquisa realizamos um estudo teórico para identificar o universo de tendências críticas e não críticas da área. Discutimos teoricamente a formação inicial e continuada e implicações na apropriação do conhecimento acerca das tendências críticas da Educação Física.

\section{Metodologia}

Para investigação foi realizada uma pesquisa de campo, em que o instrumento de coleta dos dados foi um questionário aplicado aos professores de Educação Física da rede pública municipal e estadual de Turvo. 
Segundo Gonsalves (2001, p.67):

A pesquisa de campo é o tipo de pesquisa que pretende buscar a informação diretamente com a população pesquisada. Ela exige do pesquisador um encontro mais direto. Nesse caso, o pesquisador precisa ir ao espaço onde o fenômeno ocorre, ou ocorreu e reunir um conjunto de informações documentadas [...].

O trabalho no campo apresenta-se como possibilidade de uma aproximação entre o que desejamos estudar e de criarmos um conhecimento partindo da realidade presente no campo. O pesquisador, na tarefa de descobrir respostas, necessita questionar e ir além da simples descoberta, criar e produzir conhecimentos. A relação entre os sujeitos e o referencial teórico estudado é de extrema importância. (MINAYO, 2004).

\section{Atividade docente e a necessidade da consciência pedagógica}

O trabalho do professor é uma atividade profissional, que pode se caracterizar como um trabalho intelectual, semiautônomo e em processo de desqualificação/requalificação. Este trabalho docente é um trabalho profissional, pois possui conhecimentos e habilidades próprias para exercê-lo e possui conhecimento técnico pedagógico relacionado à sua referência pedagógica.

Para Saviani (2011, p.82) o saber pedagógico é o que realmente define o trabalho do professor, pois o “melhor geografo não será necessariamente o melhor professor de Geografia, nem será o historiador aquele que desempenhará melhor o papel de professor de Historia (...)".

É muito importante que o professor de Educação Física tenha consciência e reconheça a concepção selecionada balizadora de suas aulas, pois muitos professores afirmam seguir tais tendências, mas sua prática pedagógica se explicita com base em uma perspectiva diferente, ou talvez a falta de conhecimento acerca da tendência se torna um obstáculo para a realização da mesma em sua prática pedagógica.

Para Freire (1974, p.105) a consciência é vital no processo de humanização:

Os homens ao terem consciência de sua atividade e do mundo em que estão ao atuarem em função de finalidades que propõem e se propõem, ao terem o ponto de decisão de sua busca em si e em suas relações com o mundo, e com os outros, ao impregnarem o mundo de sua presença criadora através da transformação que realizam nele, na medida em que dele podem separar-se e, separando-se, podem com ele ficar, os homens, ao contrario dos animais, não somente vivem, mas existem, e sua existência é histórica.

Podemos também concluir que o desenvolvimento de uma consciência crítica sobre a relação necessária entre teoria e prática, seria o diferencial que conduziria dialeticamente tal relação rumo à nova práxis. Portanto, o exercício da docência, enquanto ação transformadora que se renova tanto na teoria quanto na prática, requer necessariamente o desenvolvimento de uma consciência crítica. (MEDEIROS; CABRAL, 2006). 
E neste sentido podemos dizer que o exercício da ação docente requer preparo. Preparo que não se esgota nos cursos de formação, mas, para o qual há uma contribuição específica enquanto formação teórica (em que a unidade teoria e prática é fundamental) para a práxis transformadora. (MEDEIROS; CABRAL, 2006).

\section{Formação inicial e continuada na educação física}

Muito se tem discutido sobre a importância de mudanças na educação, bem como na Educação Física. Com a intenção de superar os modelos formativos mecanicista, esportivista e tradicional, muitos trabalhos procuraram discutir as questões relacionadas à formação profissional direcionada à área escolar. Consequentemente, surgiram diferentes maneiras de se abordar a formação do professor, em alguns casos influenciados pelas determinações legislativas, das novas formas de estruturação, propostas curriculares e parâmetros que sugerem mudanças em todos os níveis de ensino. (MIRANDA, 2013).

A formação inicial pode ser compreendida, também, como a fase em que ocorre o primeiro contato formal com o significado do que é ser professor e como ocorre a sua profissionalização. Trata-se de um período de construção de uma base que solidificará a sua docência com saberes até então desconhecidos, apresentando situações diferentes daquelas experimentadas durante a sua vida escolar e constituindo a porta de entrada no mundo profissional. (MIRANDA, 2013).

Por princípio, a formação inicial dos professores deverá fazer deles aquilo que esperam os sistemas educativos atuais, ou seja, deverá ser voltada a uma concepção de Educação e Pedagogia alinhada com certa concepção de Homem e Sociedade (CRÓ apud MIRANDA, 2013)

Neira (2003) considera que a formação inicial do educador é a trajetória que ele percorre desde o momento em que inicia a escolarização até a sua conclusão no ensino superior, quando o professor terá adquirido a qualificação profissional mínima e a certificação, habilitando-se legal e tecnicamente para o exercício profissional. (apud MIRANDA, 2013)

A formação continuada torna-se um grande aliado no processo de formação, traz a constante busca do conhecimento, proporcionando novas ideias e recursos para podermos contribuir de forma eficaz para os avanços e mudanças que são necessárias no âmbito escolar, na comunidade e na educação. (PADILHA, 2017).

A continuidade da formação nos remete a pensar de que forma os professores devem buscar uma maior aproximação com a continuidade dos estudos, nos remetendo aqui a função e contribuição dos sistemas de ensino no sentido de lutarem para oportunizar aos professores, a realização da continuidade da sua formação. (PADILHA, 2017).

Freitas (2007) ressalta que a defesa deve ser na direção de: 
[...] uma política global de formação e valorização dos profissionais da educação que contemple de forma articulada e prioritária a formação inicial, formação continuada e condições de trabalho, salários e carreira, com a concepção sócio-histórica do educador a orientá-la, faz parte das utopias e do ideário de todos os educadores e das lutas pela educação pública nos últimos 30 anos. (apud PADILHA, 2017, p.03).

A formação continuada compreende dimensões coletivas, estendendo-se a cursos de extensão, aperfeiçoamento, especialização, atualização, mestrado e doutorado que possam agregar novos saberes e práticas, tal como refletir o processo pedagógico, tendo como ato fundamental a busca pelo aperfeiçoamento técnico, educacional, didático, ético e político do profissional. (PADILHA, 2017).

A formação continuada de professores de Educação Física, necessita ser permanentemente repensada. Como todos os profissionais, a Educação Física enquanto campo profissional também necessita estar em constante atualização. Suas metodologias tiveram mudanças, e um profissional que não participa de uma formação continuada poderá estar aliado ou alienado a uma tendência ultrapassada de educação. (PADILHA, 2017).

\section{Tendências pedagógicas}

As concepções pedagógicas têm como objetivo tentar explicitar a finalidade da Educação Física no âmbito escolar. Muitas propostas surgiram e, apesar de no início, as ideias dos pensadores da área serem mais homogêneas, hoje temos um leque de sugestões que tentam superar o paradigma da aptidão física e dos esportes e que vem ganhando força na prática pedagógica da Educação Física no Brasil. (MARIANO, 2005).

As tendências pedagógicas gestadas a partir da década de 1980 vislumbraram delinear acerca da especificidade da área e superar a falta de legitimidade.

Existem vários autores no campo da Educação Física que se debruçaram em definir as diversas tendências que configuram essa área de conhecimento, entre eles podemos citar Bracht (1999), Darido (2003), Castellani Filho (1999). Apresentamos uma sistematização das tendências proposta por Castellani Filho, com o intuito de materializar as tendências produzidas na área. 


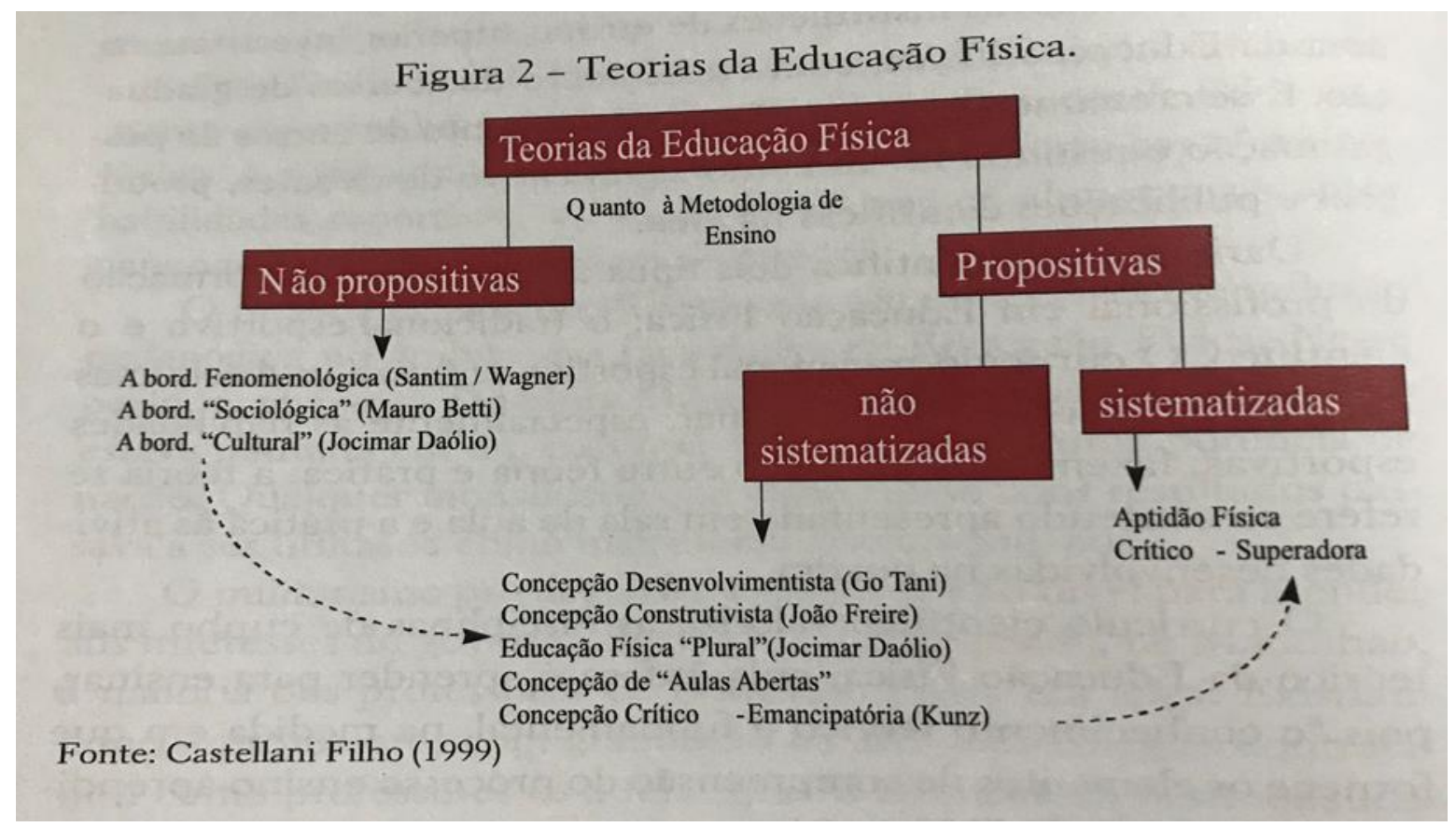

Figura 1 - Teorias da Educação Física

Fonte: Castellani Filho (1999).

Entre as tendências propostas por Castellani Filho aprofundaremos do campo conservador a psicomotricidade, construtivista, desenvolvimentista, esportivista e da aptidão física. E do campo crítico a crítico superadora, crítico emancipatória e aulas abertas.

Iniciemos pela abordagem esportivista. O período que compreende esta tendência na Educação Física é de 1964 a 1985 (FERREIRA apud FERREIRA; SAMPAIO, 2013). Na abordagem esportivista para atingir os objetivos traçados para aquele contexto histórico-político, o governo resolveu apoiar a prática de esportes na escola e a Educação Física se torna o alvo perfeito. Os professores deveriam deixar de lado os aspectos sociais, educativos e afetivos e se preocupar somente com o rendimento e o aprimoramento das habilidades esportivas (FERREIRA apud FERREIRA; SAMPAIO, 2013). A Educação Física passou a ser dominada pelos esportes, mais precisamente, passou a ser sinônimo de esportes. Há uma exclusão generalizada daqueles que não possuem habilidades, a competição passa a ser o objetivo do processo. A relação professor-aluno passa a ser técnico-atleta.

A psicomotricidade é uma abordagem que ganhou destaque nas décadas de 1970 e 1980. Tem como objetivo usar a Educação Física como uma forma de auxiliar no ensino de outras disciplinas escolares, utilizando-a como um instrumento, sem conferir-lhe uma especificidade. Esse método pedagógico ainda é bastante utilizado e é daí que deriva a abordagem desenvolvida pelo professor João Batista Freire, que também merece destaque. A 
proposta construtivista-interacionista de Freire volta sua preocupação mais especificamente à cultura infantil, que é o instrumento fundamental para o desenvolvimento motor, e ao ensino fundamental. Também tem como base teórica a psicologia do desenvolvimento e os estudos de Jean Piaget. (MARIANO, 2005).

A abordagem construtivista é baseada no construtivismo de Piaget. Darido (2003) afirma que a corrente construtivista sofreu influências da psicomotricidade, no sentido de valorizar aspectos psicológicos, afetivos e cognitivos no desenvolvimento do movimento humano. Dentro desta complexidade a construção do conhecimento se dá através da interação sujeito-mundo. Freire (1991) pode ser considerado como o responsável pela introdução desta abordagem na Educação Física Escolar. Para o autor, a criança é uma especialista no jogo, no brincar e no brinquedo; possui um conhecimento prévio que deve ser respeitado e considera o erro como um processo para a aprendizagem. O tema saúde na abordagem construtivista é, assim como na psicomotricidade, compreendido de forma indireta. (apud FERREIRA; SAMPAIO, 2013).

A tendência desenvolvimentista, que trabalha com crianças nas primeiras quatro séries do ensino fundamental, de acordo com Tani (1986) tem como objetivo oferecer aos alunos a experimentação de movimentos, visando garantir seu desenvolvimento normal, acompanhando a maturação biológica do organismo, de acordo com a idade biológica e cronológica, aceitando que possam acontecer variações de um indivíduo para o outro. Essa concepção baseia-se na psicologia do desenvolvimento e da aprendizagem, tendo como principal autor o professor Go Tani, da Universidade de São Paulo (USP). (apud MARIANO, 2005).

Por outro lado na tendência da Educação Física e saúde, a aptidão física se torna um tema importante, pois é necessário atender aos futuros atletas. A fisiologia e o treinamento esportivo, principalmente, atingem um grande desenvolvimento (FERREIRA; SAMPAIO, 2013). Podemos traçar um paralelo com o higienismo em que a Educação Física possuía como preocupação principal os hábitos de higiene e saúde, valorizando tanto o desenvolvimento físico quanto o moral, a partir do exercício. (DARIDO 2003). Sua característica principal foi a utilização da ginástica calistênica, os professores eram da área médica, não havia interação entre alunos e professor, os mais fracos e doentes eram excluídos das aulas e não havia nenhuma interação com as questões pedagógicas da escola. (apud FERREIRA; SAMPAIO, 2013).

Nos anos 90 foram adotados alguns pressupostos teóricos num referencial crítico com a tentativa de romper com o modelo que era esportivista e de aptidão física praticado nas aulas de Educação Física. As abordagens críticas começam a questionar a função da Educação Física escolar. Explicitaremos as tendências críticas, representadas nesse estudo pelas seguintes proposições: aulas abertas, crítico-superadora e crítico-emancipatoria.

A tendência das aulas abertas é representada no Brasil principalmente pelo professor alemão Reiner Hildebrandt e foi desenvolvida a partir das ideias de Trebels e Brodtmann. Considera que o trabalho dentro de uma concepção fechada impede ou ao menos inibe a formação de indivíduos autossuficientes, autônomos e críticos, ao 
contrário da concepção aberta, que colabora para o desenvolvimento dessas características, trazendo o aluno a uma coparticipação nas decisões do que deve ser trabalhado nas aulas. (MARIANO, 2005).

A tendência Crítico emancipatória visa buscar possibilidades para ensinar os esportes pela sua transformação didático-pedagógica, favorecendo uma reflexão crítica e emancipada aos alunos. Segundo Kunz (1996) o aluno tem a possibilidade de poder compreender as estruturas autoritárias dos processos institucionalizados da sociedade que formam as falsas convicções, interesses e desejos.

A construção do processo de ensino se da por três categorias: trabalho, interação e linguagem. "Assim, um ensino que se concentrar em apenas uma dessas três categorias [...], torna-se uma 'redução de complexidade' e tem consequências sobre o futuro desenvolvimento do jovem educando." (KUNZ, 1996, p. 47). As categorias de trabalho, interação e linguagem expressam-se em competências humanas a saber, as competências objetiva, social e comunicativa respectivamente.

Para a competência objetiva o aluno precisa receber conhecimento e aprender algumas estratégias para o agir. Para a competência social vale os conhecimentos e os esclarecimentos que o aluno deve adquirir para que consiga entender as relações socioculturais no contexto em que vive. A competência comunicativa tem um papel decisivo nas aulas, em que entender a comunicação dos outros e saber se comunicar é um processo reflexivo que desencadeia iniciativas do pensamento crítico (KUNZ, 1996).

A tendência crítico-superadora elaboradora por um Coletivo de Autores sustenta que o professor de Educação Física deve ser um educador comprometido com um projeto político e pedagógico. Político porque encaminha as propostas de intervenção em determinadas direções; e pedagógico porque possibilita a reflexão a respeito das ações do homem na realidade. (COLETIVO DE AUTORES, 1996).

Nessa tendência, os movimentos são caracterizados pela luta entre as classes sociais, a fim de afirmarem seus interesses. Essa luta tem como objetivo transformar a sociedade para que os trabalhadores possam usufruir do resultado de seu trabalho. (COLETIVO DE AUTORES, 1996).

Para a seleção e organização das aulas são apontados alguns princípios para o trato com o conhecimento. Os princípios são: relevância social dos conteúdos, contemporaneidade do conteúdo e adequação às possibilidades sócio-cognoscitivas do aluno. Para a organização e sistematização dos conteúdos os princípios metodológicos são: confronto e contraposição dos saberes, simultaneidade dos conteúdos, espiralidade da incorporação das referências do pensamento, e provisoriedade do conhecimento. (COLETIVO DE AUTORES, 1996).

\section{Apresentação e análise dos dados}

Os dados foram coletados a partir de um questionário em que objetivamos compreender o conhecimento que os professores de Educação Física possuem sobre as tendências críticas da Educação Física. O mesmo foi 
aplicado com os professores de Educação Física da rede pública, sendo uma escola da rede municipal e duas da rede estadual do município de Turvo, totalizando oito docentes. No entanto somente cinco professores devolveram o questionário respondido. O questionário conteve onze perguntas e foi aplicado conforme agendamento decidido com os professores. Os dados foram analisados em uma abordagem qualitativa e quantitativa. A análise quantitativa se vincula ao resultado numérico dos dados coletados, por outro lado na abordagem qualitativa, são apontadas características mais particulares. Sendo essa abordagem considerada a mais complexa de interpretar os dados por contar com infinitas circunstâncias. (MINAYO, 2004).

O questionário foi aplicado entre os dias 23/04/2018 e 11/05/2018. O quadro abaixo trata de aspectos que constituem a identidade profissional dos professores participantes desse estudo.

Quadro 1 - identidade profissional

\begin{tabular}{|c|c|c|c|c|c|}
\hline PROFESSOR & $\begin{array}{c}\text { ANO DE } \\
\text { FORMAÇÃO }\end{array}$ & $\begin{array}{c}\text { TEMPO DE } \\
\text { ATUAÇÃ̃ }\end{array}$ & ESPECIALIZAÇÃO & $\begin{array}{c}\text { FORMAÇÃO } \\
\text { CONTINUADA } \\
\text { (FREQUENCIA) }\end{array}$ & UNIVERSIDADE \\
\hline A & 2013 & 7 anos & Sim & Anualmente & UNESC \\
\hline B & 2013 & 5 anos & Sim & A cada 2 meses & UNESC \\
\hline C & 2015 & 6 anos & Sim & Anualmente & ESUCRI \\
\hline D & 1984 & 23 anos & Sim & Anualmente & UFSC \\
\hline E & 2012 & 12 anos & Sim & Anualmente & UNESC \\
\hline
\end{tabular}

Fonte: Ferreira (2018)

De acordo com o quadro acima percebemos que quatro dos professores pesquisados possuem ano de formação muito próxima, entre 2012 a 2015, sendo três deles formados na mesma universidade UNESC (Universidade do Extremo Sul Catarinense), o que nos faz concluir que sua formação inicial se deu em uma mesma matriz curricular, sendo os outros de instituições diferentes como UFSC (Universidade Federal de Santa Catarina) e ESUCRI (Escola Superior de Criciúma). Apenas o professor D realizou a formação na década de 80 do século passado. Os professores A B e C possuem tempo de formação próxima, com apenas 1 e 2 anos de diferença. O professor E diz possuir 12 anos de tempo de atuação. Essa informação causa certa estranheza, pois formado em 2012, até este ano de 2018 somaria apenas 6 anos de atuação, mas podemos levar em consideração que o mesmo possa ter contabilizado os anos que realizou estágio não obrigatório.

Todos os pesquisados afirmaram realizar formação continuada. O professor B realiza a cada dois meses, porém quatro professores realizam a mesma uma vez por ano descaracterizando o sentido da formação continuada. Vitório (2013) esclarece que nesse caso o que encontramos é uma formação descontinuada.

O conhecimento superficial emperra a mudança, a superação do modelo que está colocado e reforça a continuidade da formação na descontinuidade de tempo e conhecimento, ou seja, confirma que houve formação continuada, mas caracterizada como: a continuidade da descontinuidade. (p.137). 
Quadro 2 - Tendências pedagógicas da Educação Física

\begin{tabular}{|c|l|c|c|}
\hline Professor & \multirow{2}{|c|}{$\begin{array}{c}\text { Tendências } \\
\text { pedagógicas da } \\
\text { Educação Física }\end{array}$} & \multicolumn{2}{|c|}{ Quais } \\
\cline { 3 - 4 } & Sim & Tecnicista, Tradicional & $\begin{array}{c}\text { Cuperadora, } \\
\text { Emancipatória }\end{array}$ \\
\hline A & Sim & $\begin{array}{c}\text { Higienista, Militarista, } \\
\text { Pedagogicista, Esportivista }\end{array}$ & $\begin{array}{c}\text { Superadora, } \\
\text { Emancipatória }\end{array}$ \\
\hline B & Sim & Construtivista & Superadora \\
\hline C & Sim & Psicomotricidade & --- \\
\hline D & Sim & --- & --- \\
\hline E & & & \\
\hline
\end{tabular}

Fonte: Ferreira (2018)

Se a resposta da pergunta sobre o conhecimento das tendências pedagógicas fosse positiva, deveriam responder onde aprenderam sobre elas e todos os pesquisados responderam conhecer. Para o professor A essa aprendizagem se deu na Licenciatura em Educação Física, na pós-graduação e na formação continuada que realizou. Os professores B C e E afirmaram ter aprendido sobre elas na Licenciatura em Educação Física. Ou seja, durante sua formação inicial. Para Miranda (2013) a formação inicial trata-se de um período de construção de uma base que solidificará a sua docência com saberes até então desconhecidos, apresentando situações diferentes daquelas experimentadas durante a sua vida escolar e constituindo a porta de entrada no mundo profissional. $\mathrm{O}$ professor D respondeu ter conhecido em um curso particular. Isso reforça a importância da formação continuada. Que segundo Padilha:

A contribuição da mesma caracteriza-se como uma forma de melhoria de qualidade de ensino. Evidenciando assim a importância de um saber contínuo, a promoção de espaços para que se possa aperfeiçoar seus conhecimentos, nos quais também possa aprofundar a discussão, levando o professor a refletir sobre como e por que, desenvolvendo simultaneamente uma reflexão da sua ação, ou seja da práxis. (2017, p.03).

Pois foi por meio de uma formação continuada que o professor D acessou conhecimento sobre a psicomotricidade. Ele justificou que em sua formação inicial foi discutido os métodos e não tendências pedagógicas.

Os pesquisados também foram questionados se seguiam alguma tendência pedagógica em suas aulas e por que. Apenas o professor D não respondeu. O professor A respondeu "todas, porque uma completa a outra e auxilia 
em certos momentos". No entanto sobre utilizar as tendências pedagógicas conservadoras junto com críticas. Libâneo explica que não há como fazer um "mix" dessas tendências, pois, a pedagogia liberal sustenta a ideia de que a escola tem por função preparar os indivíduos para o desempenho de papéis sociais, de acordo com as aptidões individuais. (LIBÂNEO, 1992, p. 02).

Por outro lado nas tendências críticas, a atuação da escola consiste na preparação do aluno para o mundo adulto e suas contradições, fornecendo-lhe um instrumental, por meio da aquisição de conteúdos e da socialização, para uma participação organizada e ativa na democratização da sociedade. (LIBANÊO, 1992, p. 13).

O professor B disse seguir a crítico emancipatória, "porque contribui para uma reflexão crítica, valorizando as competências objetivas, sociais e comunicativas". Com essa resposta podemos observar que o pesquisado mostra conhecimento sobre a tendência que diz seguir, já que a construção do processo de ensino se dá por três categorias: trabalho sendo competência objetiva, interação sendo competência social e linguagem sendo competência comunicativa. "Assim, um ensino que se concentrar em apenas uma dessas três categorias [...], tornase uma 'redução de complexidade' e tem consequências sobre o futuro desenvolvimento do jovem educando." (KUNZ, 1996, p. 47).

O professor C disse seguir a crítico superadora, porque acha que é a que "mais se encaixa com o ideal para abranger um todo". A resposta deste professor demonstra falta de conhecimento sobre a tendência que diz seguir. Nessa tendência, os movimentos sociais são caracterizados pela luta entre as classes sociais, a fim de afirmarem seus interesses. Essa luta tem como objetivo transformar a sociedade para que os trabalhadores possam usufruir do resultado de seu trabalho. (COLETIVO DE AUTORES, 1996).

O professor D disse seguir a psicomotricidade, porque "trabalha o individuo num todo, nos aspectos físicos, motor e psíquico", mostrando ter conhecimento sobre a tendência que diz seguir. A psicomotricidade tem como objetivo usar a Educação Física como uma forma de auxiliar no ensino de outras disciplinas escolares, utilizando-a como um instrumento, sem conferir-lhe uma especificidade. (MARIANO, 2013).

Quando questionados se existe alguma diferença entre as tendências pedagógicas da Educação Física do campo crítico e do campo conservador, pedindo para justificar sua resposta, dos cinco pesquisados todos assinalaram que sim, existe diferença, mas apenas dois justificaram.

O professor A respondeu que sim, pois “uma da voz ao aluno que seria a crítica enquanto a conservadora o professor é o centro do conhecimento e da aula". O professor B respondeu que sim, e disse que "nas tendências conservadoras o enfoque é ligado somente ao aprender fazer, já nas tendências críticas o educando aprende mais que o fazer".

Os pesquisados foram questionados se já receberam estagiários da UNESC ou de alguma outra instituição e em que medida a atuação do estagiário influenciou em seu conhecimento sobre as tendências pedagógicas da Educação Física. O professor A recebeu da UNESC e de outras instituições e justificou dizendo que "aprendeu 
mais em relação às atividades e um pouco de como se trabalhar com determinadas faixas etárias e ajudou na sua avaliação como professor". O professor B recebeu apenas de outra instituição e disse não ter tido influência, os professores C e E receberam da UNESC e outras instituições, mas não justificaram e o professor D recebeu apenas da UNESC e disse não ter tido influência.

\section{Considerações finais}

O desenvolvimento do presente estudo possibilitou uma análise para compreender qual o conhecimento dos professores de Educação Física das escolas públicas de Turvo, possuem sobre as tendências pedagógicas críticas da Educação Física. O instrumento utilizado para coleta de dados e análise foi uma pesquisa de campo. Com o propósito de analisar com maior consistência os dados foi necessário qualificar nosso entendimento sobre as tendências pedagógicas da Educação Física, da formação inicial e da formação continuada. Evidentemente essas temáticas são muito importantes no desenvolvimento profissional e ao mesmo tempo que o estudo destas ofereceu subsídios para a leitura dos elementos surgidos na pesquisa, solidificaram minha formação inicial.

É de suma importância que o professor de Educação Física tenha consciência e conhecimento da concepção balizadora de suas aulas. Trago as tendências pedagógicas críticas da Educação Física como importantes, pois essas dão voz ao aluno deixando que participe da sua formação. Essas tendências críticas visam possibilitar ao aluno uma reflexão sobre o mundo em que está inserido, para que sejam críticos e autônomos. Podemos também concluir que o desenvolvimento de uma consciência crítica sobre a relação necessária entre teoria e prática, seria o diferencial que conduziria dialeticamente tal relação rumo à nova práxis. (MEDEIROS; CABRAL, 2006).

Este trabalho não tem a intenção de desqualificar nenhum dos professores pesquisados, em relação a sua responsabilidade e compromisso com o processo pedagógico. Procuramos especificamente, no limite imposto pela pesquisa, aferir o conhecimento dos professores sobre as propostas críticas da Educação Física. Descartamos a questão do período de formação como fator de precariedade de conhecimento e informação sobre o assunto, considerando que quatro dos professores tiveram sua formação já na segunda década dos anos 2000 .

Quanto à utilização de propostas críticas um dos professores não respondeu e outro professor utiliza a psicomotricidade. Então são três os professores que adotam as propostas críticas. Contudo algumas imprecisões foram percebidas em relação à utilização da crítico-superadora e de uma tentativa por parte de um dos professores de utilizar várias propostas de forma articulada.

A partir dos dados, foi evidenciado que os pesquisados possuem conhecimento sobre as tendências pedagógicas da Educação Física, porém mais especificamente sobre as tendências críticas, apenas três dos pesquisados conseguiram desenvolver considerações a respeito. Também é relevante a afirmação de todos os pesquisados de que compreendem haver diferenças entre as propostas tradicionais e as críticas, muito embora 
apenas dois tenham justificado a resposta. Nos parece significativo que as justificativas, não obstante apresentarem relativa fragilidade, são coerentes com os marcos teóricos utilizados nesse trabalho.

Portanto, ao final da pesquisa é possível afirmar que os professores A e B conhecem amplamente as tendências críticas da Educação Física, o professor C e E conhecem parcialmente, já que o C afirma utilizar delas, mas não soube explicá-las corretamente e o professor E afirma conhecer, mas não falou sobre. Já o professor D não conhece as tendências críticas.

Um aspecto que pode ser apontando como limite da pesquisa, foi o retorno do questionário dos professores, pois cinco (05) retornaram em um universo de oito (08) professores.

Para um enriquecimento da pesquisa, acredito que a observação de algumas aulas dos professores pesquisados poderia ampliar horizontes de análise.

Existem poucos estudos sobre o conhecimento dos professores de Educação Física sobre as tendências críticas da Educação Física ou sobre a importância da sua utilização. Embora as informações resultantes dessa pesquisa não sejam generalizáveis, espera-se contribuir para oferecer subsídios para pesquisas futuras.

\section{Referências}

BRACHT, Valter. A constituição das teorias pedagógicas da Educação Física. Cadernos Cedes, ano 19, vol. 19, n.48, p. 69-88, ago. 1999.

CASTEllani FILHO, Lino. A Educação Física no sistema educacional brasileiro: Percurso, paradoxos e perspectivas". Tese (Doutorado em Educação) - Faculdade de Educação da Unicamp, Campinas, 1999.

COLETIVO DE AUTORES. Metodologia do Ensino da Educação Física. São Paulo: Cortez, 1996.

CORRÊA, Ivan Livindo de Senna, MORO, Roque Luiz. Educação Física Escolar: reflexão e ação curricular. Ijuí: Unijuí, 2004.

DARIDO, Suraya Cristina. Educação Física na escola: questões e reflexões. Rio de Janeiro, RJ: Editora Guanabara Koogan, 2003.

FERREIRA, Heraldo Simões, SAMPAIO, José Jackson Coelho. Tendências e abordagens pedagógicas da Educação Física escolar e suas interfaces com a saúde. 2013. Síntese. Disponível em: http://www.efdeportes.com/efd182/tendencias-pedagogicas-da-educacao-fisica-escolar.htm. Acesso em: 05 abr. 2018.

FREIRE, Paulo. Pedagogia do oprimido. Rio de Janeiro: Paz e Terra, 1974.

GONSALVES, Elisa Pereira. Iniciação a pesquisa científica. Campinas, SP: Alínea, 2001.

KUNZ, Elenor. Transformação didático-pedagógica do Esporte. Ijuí: Unijuí, 1996.

LIBÂNEO, José Carlos. Tendências pedagógicas na prática escolar. In: Democratização da Escola Pública - a pedagogia crítico-social dos conteúdos. São Paulo: Loyola, 1992. 
MARIANO, Marina. As concepções pedagógicas da Educação Física e suas aplicações nas escolas: o caso da rede pública de ensino fundamental em Campinas $-5^{\mathrm{a}}$ a $8^{\mathrm{a}}$ série. 2005. 40f. Monografia (Graduação em Educação Física) - Faculdade de Educação Física, Universidade Estadual de Campinas, Campinas, 2005. Disponível em: file:///C:/Users/lab9/Downloads/MarianoMarina_TCC.pdf. Acesso em: 30 nov. 2017.

MEDEIROS, Marinalva Veras; CABRAL, Carmen Lúcia de Oliveira. Formação Docente: da teoria à prática em uma abordagem sócio-histórica. Revista E-curriculum, São Paulo, v.1, n.2, junho de 2006. Disponível em http://www.pucsp.br/ecurriculum. Acesso em: 26 mai. 2018.

MINAYO, M. C. de S. Ciência, técnica e arte: o desafio da pesquisa social. In: MINAYO, M. C. de S. (org.). Pesquisa social. 17.ed. Rio de Janeiro: Vozes, 2004.

MIRANDA, Simone de. Formação inicial do professor de educação física. Curitiba. 2013. 14f. Disponível em: http://educere.bruc.com.br/arquivo/pdf2013/14122 6483.pdf. Acesso em: 18 de Abr. 2018.

PADILHA, Vitória Espindola. Formação continuada do professor de Educação Física: possíveis articulações com a formação docente. 2017. 10f. Trabalho de conclusão de curso. UNESC. Criciúma. 2017.

SAVIANI, Dermerval. Pedagogia histórico-crítica: primeiras aproximações. 11.ed.rev.- Campinas, SP: Autores Associados, 2011. - (Coleção educação contemporânea).

VITÓRIO, Vânia. O conhecimento em Educação Física na formação continuada em Santa Catarina. Dissertação (Dissertação em mestrado na educação) UNESC. Criciúma, p.208. 2013.

\section{Como citar este artigo}

FERREIRA, Loisleine Fernandes; CARDOSO, Ana Lúcia. O conhecimento dos professores de educação física do município de Turvo/SC acerca das tendências pedagógicas críticas. Revista Kinesis, Santa Maria, v. 37, p. 01-15, 2019. 